\title{
EVALUASI KESESUAIAN LAHAN AKTUAL TAMBAK YANG ADA DI KABUPATENTANJUNG JABUNG BARAT PROVINSI JAMBI
}

\author{
Rachmansyah dan Akhmad Mustafa \\ Balai Riset Perikanan Budidaya Air Payau \\ Jl. Makmur Dg. Sitakka No. 129, Maros 90512, Sulawesi Selatan \\ E-mail: rachman222000@yahoo.com
}

(Naskah diterima: 18 April 2011 ; Disetujui publikasi: 11 Juli 2011)

\begin{abstract}
ABSTRAK
Tambak di Kabupaten Tanjung Jabung Barat (Tanjabbar), Provinsi Jambi memiliki produktivitas yang relatif rendah dan telah ditetapkan sebagai salah satu lokasi pengembangan kawasan Minapolitan. Oleh karena itu, dilakukan penelitian untuk menentukan kesesuaian lahan tambak yang ada demi peningkatan produktivitas tambak serta mendukung program pengembangan kawasan Minapolitan di Kabupaten Tanjabbar. Faktor yang dipertimbangkan dalam evaluasi lahan adalah: topografi dan elevasi, hidrologi, tanah, dan iklim. Analisis spasial dalam Sistem Informasi Geografis digunakan untuk penentuan kesesuaian lahan budidaya tambak. Hasil penelitian menunjukkan bahwa lahan tambak di Kabupaten Tanjabbar didominasi tanah sulfat masam dengan unsur- unsur toksik yang tinggi dan sebaliknya unsur hara makro yang rendah dengan tekstur tanah dominan lempung berliat dan lempung berpasir. Topografi lahan umumnya relatif datar dan elevasi yang tergolong rendah. Salinitas air tergolong rendah dengan tingkat turbiditas yang tergolong tinggi serta pasang surut yang sangat tinggi $(4,55 \mathrm{~m})$. Curah hujan yang mencapai $2.393 \mathrm{~mm} /$ tahun dengan 2 bulan kering. Hasil analisis kesesuaian lahan aktual menunjukkan bahwa tambak yang ada di Kabupaten Tanjabbar seluas $617,14 \mathrm{ha}$, di mana tidak ada lahan tambak yang tergolong sangat sesuai (Kelas S1); 38,40 ha tergolong cukup sesuai (Kelas S2); dan 222,82 ha yang tergolong kurang sesuai (Kelas S3); dan 355,92 ha yang tergolong tidak sesuai (Kelas N).
\end{abstract}

KATA KUNCl: kesesuaian lahan, tambak, Kabupaten Tanjung Jabung Barat

ABSTRACT: Actual land suitability evaluation of existing brackishwater ponds in Tanjung Jabung Barat Regency, Jambi Province. By Rachmansyah and Akhmad Mustafa

Brackishwater ponds in Tanjung Jabung Barat Regency, Jambi Province has low productivity. The area has also been designated as one of Minapolitan areas in Jambi Province. Therefore, the recent research was conducted to determine land suitability of the existing brackishwater ponds in the area which was hoped to serve as the baseline data for any programm to increase the brackishwater ponds productivity and also to support the development of the Minapolitan area. Factors considered in the land evaluation were topography and elevation, hydrology, soil along with climate. Spatial analysis in Geographical Information System was used to determine land suitability for brackishwater ponds. The results of the research show that soil in the brackishwater ponds of Tanjung Jabung Barat Regency is dominated by acid sulfate soil with high concentration of toxic elements. Low concentration of macro nutrient with soil texture dominated by clay loam and sandy loam is also the characteristics 
of the area. Generally, its land topography is flat and the elevation is classified low. Water salinity is low with high turbidity. The area has also a very high tidal range $(4.55 \mathrm{~m})$. Rainfall can reach $2.393 \mathrm{~mm} /$ year with 2 dry months. The result of actual land suitability showed that the existing brackishwater pond in Tanjung Jabung Barat Regency was 617.14 ha, of which no brackishwater ponds land was classified as highly suitable (S1 Class). A total of 38.40 ha was classified as moderately suitable (S2 Class), 222.82 ha classified as marginally suitable (S3 Class) and 355.92 ha was lassified as unsuitable (N Class).

\section{KEYWORDS: land suitability, brackishwater pond, Tanjung Jabung Barat Regency}

\section{PENDAHULUAN}

Salah satu kabupaten di Provinsi Jambi yang memiliki lahan tambak dan potensi lahan tambak adalah Kabupaten Tanjung Jabung Barat (Tanjabbar). Namun demikian, tambak yang ada, masih memiliki tingkat produktivitas tambak yang tergolong rendah. Komoditas yang dibudidayakan di tambak Kabupaten Tanjabbar adalah udang windu (Penaeus monodon) dan ikan bandeng (Chanos chanos). Komoditas lain yang dapat dibudidayakan di tambak adalah udang vaname (Litopenaeus vannamei) dan rumput laut (Gracilaria verrucosa). Berdasarkan Keputusan Menteri Kelautan dan Perikanan Republik Indonesia Nomor KEP 32/ MEN/ 2010 Tentang Penetapan Kawasan Minapolitan telah ditetapkan Kabupaten Tanjabbar sebagai salah satu lokasi pengembangan kawasan Minapolitan di Indonesia dengan komoditas andalan udang. Komoditas tersebut termasuk komoditas perikanan yang berbasis lahan, maka untuk dapat tumbuh atau hidup dan berproduksi secara optimum memerlukan persyaratanpersyaratan lahan tertentu yang dapat berbeda satu sama lain.

Lahan adalah suatu lingkungan fisik yang terdiri atas tanah, topografi, hidrologi, vegetasi, dan iklim di mana pada batas- batas tertentu mempengaruhi kemampuan penggunaan lahan (World Bank, 1995 dalam Rajitha et al., 2007). Oleh karena itu, perbedaan kombinasi penyusun lingkungan fisik lahan tersebut akan memberikan karakteristik lahan yang berbeda dan pada akhirnya kesesuaian lahan yang berbeda pula.

Sistem evaluasi Iahan yang sering digunakan di Indonesia yaitu: klasifikasi kemampuan lahan dan klasifikasi kesesuaian Iahan. Klasifikasi kemampuan lahan digunakan untuk penggunaan lahan bersifat umum (dalam arti luas), sedangkan klasifikasi kesesuaian lahan digunakan untuk penggunaan lahan yang lebih bersifat khusus (Hardjowigeno, 2003). Evaluasi kesesuaian Iahan untuk budidaya tambak perlu dilakukan agar menjadi dasar pertimbangan dalam pengambilan keputusan tentang penggunaan lahan yang cocok dengan kesesuaiannya. Menurut Rossiter (1996), evaluasi kesesuaian lahan sangat penting dilakukan karena lahan memiliki sifat fisik, sosial, ekonomi, dan geografi yang bervariasi atau lahan diciptakan tidak sama.

Evaluasi kesesuaian Iahan merupakan suatu proses pendugaan keragaan Iahan apabila lahan digunakan untuk tujuan tertentu (FAO, 1985). Evaluasi kesesuaian lahan memprediksi keragaan lahan mengenai keuntungan yang diharapkan dari penggunaan lahan dan kendala penggunaan lahan yang produktif serta degradasi lingkungan yang diperkirakan akan terjadi karena penggunaan Iahan. Kesesuaian Iahan merupakan suatu kunci sukses dalam kegiatan akuakultur yang mempengaruhi keberhasilan dan keberIanjutannya (Pérez et al., 2003) serta merupakan langkah awal bagi pengembangan ilmu pengetahuan dan akuakultur yang berkelanjutan (Karthik et al., 2005). Kesesuaian lahan untuk akuakultur sebaiknya memberikan tekanan seminimum mungkin terhadap lingkungan, memberikan potensial maksimum bagi pertumbuhan komoditas, meminimumkan biaya produksi dan meminimumkan atau mencegah potensial konflik antarpengguna (Pérez et al., 2003) dan membuat penggunaan lahan lebih rasional (Hossain \& Das, 2010). Kesesuaian lahan tersebut dapat dinilai untuk kondisi saat ini (kesesuaian lahan aktual) atau setelah diadakan perbaikan (kesesuaian lahan potensial). Kesesuaian lahan aktual adalah kesesuaian lahan berdasarkan data sifat biofisik lahan sebelum lahan tersebut diberikan masukan- masukan yang diperlukan untuk mengatasi kendala (Ritung et al., 2007). 
Oleh karena itu, dilakukan penelitian yang bertujuan untuk mengevaluasi kesesuaian lahan aktual tambak yang ada agar produktivitas tambak dapat meningkat dan berkelanjutan serta dapat menjadi acuan Pemerintah Kabupaten Tanjabbar secara khusus dan Pemerintah Provinsi Jambi secara umum dalam penentuan Rencana Tata Ruang Wilayah dan mendukung program pengembangan kawasan Minapolitan.

\section{BAHAN DAN METODE}

Penelitian dilaksanakan di wilayah pesisir Kecamatan Seberang Kota, Tungkal Ilir, dan Kuala Betara (Gambar 1) yang merupakan wilayah yang memiliki tambak di Kabupaten Tanjabbar Provinsi Jambi pada bulan April dan Mei 2010.

Data primer yang dikumpulkan meliputi data biofisik lahan yang meliputi faktor: topografi, elevasi, tanah, dan hidrologi. Penentuan titik- titik pengambilan contoh tanah didasarkan pada peta Satuan Unit. Peubah kualitas tanah yang diukur langsung di lapangan adalah $\mathrm{pH}_{\mathrm{F}}(\mathrm{pH}$ tanah yang diukur di lapangan) dengan $\mathrm{pH}$ - meter (Ahern \& Rayment, 1998) dan $\mathrm{pH}_{\text {Fox }}(\mathrm{pH}$ tanah yang diukur di lapangan setelah dioksidasi dengan hidrogen peroksida $\left(\mathrm{H}_{2} \mathrm{O}_{2}\right) 30 \%$ dengan $\mathrm{pH}$ - meter (Ahern \& Rayment, 1998) serta potensial redoks dengan redox-meter. Contoh tanah diambil pada kedalaman tanah 0-0,2 m dari permukaan tanah. Untuk analisis peubah kualitas tanah lainnya, maka contoh tanah yang ada secepatnya dimasukkan dalam kantong plastik dan selanjutnya dimasukkan dalam cold box yang diberi es. Contoh tanah diovenkan pada suhu $80^{\circ} \mathrm{C}-85^{\circ} \mathrm{C}$ selama 48 jam (Ahern \& Blunden, 1998). Setelah kering, contoh tanah dihaluskan dengan cara ditumbuk pada lumpang porselin dan diayak dengan ayakan ukuran lubang $2 \mathrm{~mm}$ dan selanjutnya dianalisis di Laboratorium Tanah Balai Riset Perikanan Budidaya Air Payau (BRPBAP) di Maros. Kualitas tanah yang dianalisis di laboratorium meliputi $\mathrm{pH}_{\mathrm{KCI}}(\mathrm{pH}$ dari ekstrak $\mathrm{KCl})(\mathrm{McElnea} \&$ Ahern, 2004a), $\mathrm{pH}_{\mathrm{ox}}$ (McElnea \& Ahern, 2004b), $\mathrm{S}_{\mathrm{p}}$ (sulfur peroksida) (Melville, 1993; McElnea \& Ahern, 2004c), $\mathrm{S}_{\mathrm{KCI}}$ (sulfur yang diekstrak dengan KCl) (Melville, 1993; McElnea dan Ahern, 2004d), $S_{\text {POS }}\left(S_{P}-S_{K C I}\right)$ (Ahern \& McElnea,

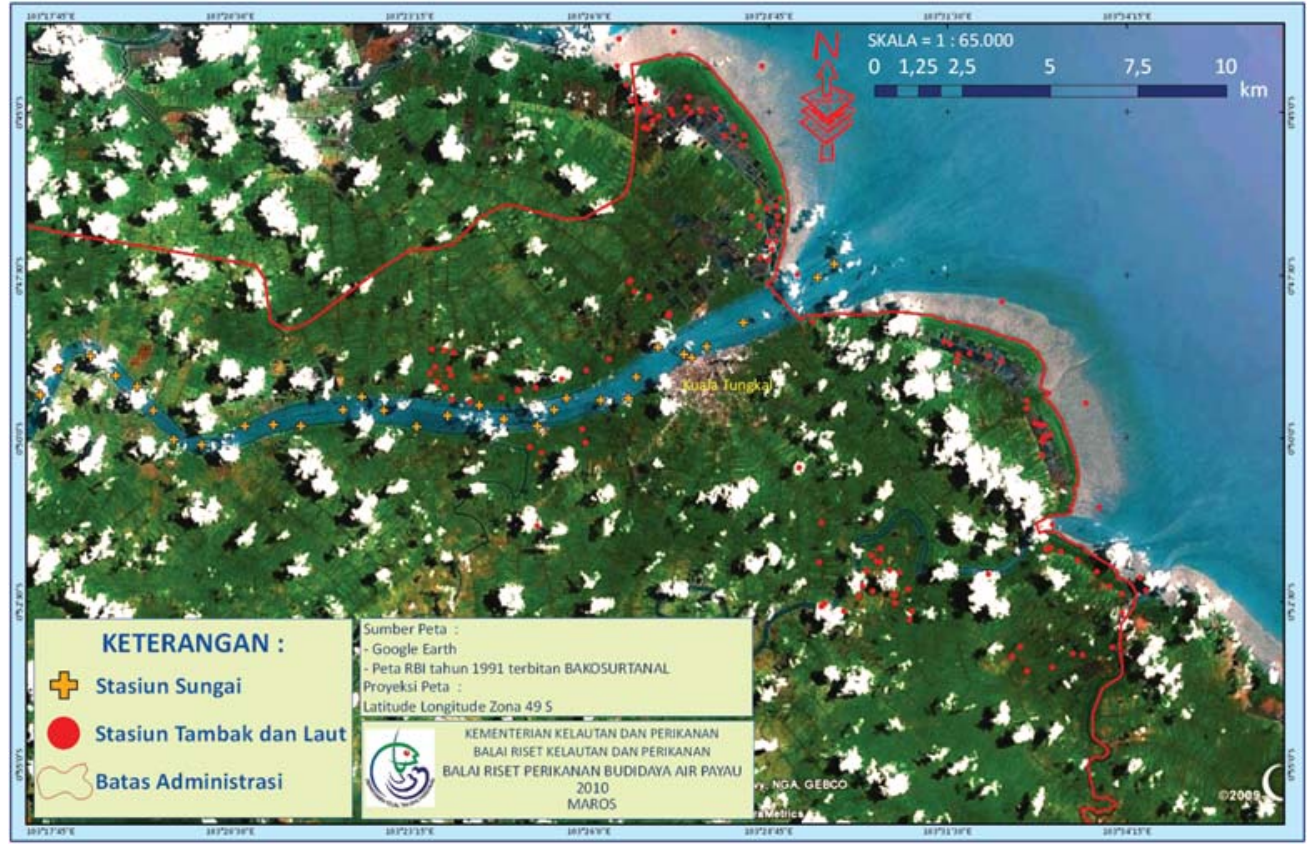

Gambar 1. Titik- titik pengukuran dan pengambilan contoh tanah dan air di kawasan pesisir Kabupaten Tanjung Jabung Barat Provinsi Jambi

Figure 1. Soil and water measurement sampling points in the coastal area of Tanjung Jabung Barat Regency Jambi Province 
2004), TPA (Titratable Peroxide Acidity atau sebelumnya dikenal dengan Total Potential Acidity) (McElnea dan Ahern, 2004b), TAA (Titratable Actual Acidity atau sebelumnya dikenal dengan Total Actual Acidity) (McElnea \&Ahern, 2004a), TSA (Titratable Sulfidic Acidity atau sebelumnya dikenal dengan Total Sulfidic Acidity) (TPA- TAA) (McElnea \& Ahern, 2004b), pirit (Ahern et al., 1998a; 1998b), karbon organik dengan metode Walkley dan Black (Sulaeman et al., 2005), N- total dengan metode Kjedhal (Sulaeman et al., 2005), $\mathrm{PO}_{4}$ dengan metode Bray 1 (Sulaeman et al., 2005), Fe dengan spektrofotometer (Menon, 1973), Al dengan spektrofotometer (Menon, 1973) dan tekstur dengan metode hidrometer (Agus et al., 2006).

Topografi dan elevasi diketahui melalui pengamatan di lapangan. Data hidrologi yang diukur adalah pasang surut dan kualitas air. Pengukuran pasang surut dilakukan di salah satu titik pengamatan yang terletak muara Sungai Tungkal. Pengukuran pasang surut dilakukan selama 39 jam dengan interval pengukuran 1 jam menggunakan palem atau rambu pengamat pasang surut. Pengukuran dan pengambilan contoh air dilakukan di sungai, laut, saluran, dan tambak pada pukul antara 09:00 dan 15:00 WB. Pengukuran dan pengambilan contoh air di tambak mengikuti titik pengambilan contoh tanah. Peubah kualitas air yang diukur langsung di lapangan adalah suhu, salinitas, oksigen terlarut, dan pH dengan menggunakan YSI 650. Contoh air untuk analisis di laboratorium diambil dengan menggunakan Kemmerer Water Sampler dan dipreservasi mengikuti petunjuk APHA (2005). Peubah kualitas air yang dianalisis di Laboratorium Air BRPBAP di Maros meliputi: $\mathrm{NH}_{4}, \mathrm{NO}_{3}, \mathrm{NO}_{2}$, dan mengikuti petunjuk Menon (1973) dan APHA (2005). Seluruh titik-titik pengamatan dan pengambilan contoh ditentukan titik koordinatnya dengan menggunakan Global Positioning System (GPS).

Data sekunder termasuk data curah hujan dikumpulkan melalui penelusuran berbagai laporan, pustaka dan hasil penelitian dari berbagai instansi terkait. Peta yang dikumpulkan antara lain peta Administrasi Kabupaten Tanjabbar.

Peta Penutup/Penggunaan Lahan yang digunakan adalah citra dari Google Earth yang diintegrasikan dengan peta dasar dari peta Rupabumi Indonesia. Data primer, sekunder dan peta Penutup/ Penggunaan Lahan yang sudah dikumpulkan, selanjutnya dilakukan pengolahan data dengan menggunakan analisis spasial dalam Sistem Informasi Geografis (SIG). Pada proses analisis menggunakan program ArcView 3.3 dengan cara memasukkan setiap peubah data untuk menghasilkan peta tematik bagi setiap peubah data. Selanjutnya dilakukan proses tumpang tindih pada semua peubah yang masuk dalam criteria kesesuaian lahan tambak. Kriteria yang digunakan dalam penentuan kesesuaian lahan untuk budidaya tambak mengacu pada kriteria yang ada (Mustafa et al., 2007).

Asumsi yang diterapkan dalam evaluasi kesesuaian lahan tambak disesuaikan pada pengelolaan yang rendah atau sederhana sampai sedang. Infrastruktur, aksesibilitas dan pemasaran hasil produksi tidak dipertimbangkan dalam evaluasi kesesuaian lahan ini. Hasil proses penilaian kesesuaian lahan ditampilkan dalam bentuk sistem klasifikasi kesesuaian lahan aktual. Sistem klasifikasi kesesuaian lahan ditentukan sampai tingkat kategori Kelas.

\section{HASIL DAN BAHASAN}

\section{Elevasi dan Topografi}

Kawasan pesisir dan daerah aliran sungai di Kabupaten Tanjabbar umumnya memiliki kemiringan lereng yang tergolong datar dan elevasi yang rendah (Anonim, 2009). Chanratchakool et al. (1995) menyarankan lahan yang baik untuk budidaya tambak adalah relatif datar. Lokasi tambak sebaiknya dipilih di tempat yang mempunyai elevasi tertentu agar memudahkan pengelolaan air, sehingga tambak cukup mendapatkan air pada saat terjadi pasang harian dan dapat dikeringkan pada saat surut harian (Poernomo, 1989). Menurut Bose et al. (1991), elevasi dasar tambak yang ideal adalah apabila dasar tambak dapat dikeringkan kapan saja dan dapat diisi air secara gravitasi selama 5 hari dari setiap siklus pasang surut.

\section{Hidrologi}

Pasang surut yang terukur di Sungai Tungkal menunjukkan bahwa perbedaan pasang dan surut di Kabupaten Tanjabbar tergolong sangat tinggi yaitu mencapai 4,55 $\mathrm{m}$. Penurunan tinggi air tergolong cepat, di mana terjadi penurunan tinggi air sebesar 2,68 $\mathrm{m}$ dalam waktu 1 jam setelah pasang tinggi (Gambar 2). Poernomo (1989) berpendapat 


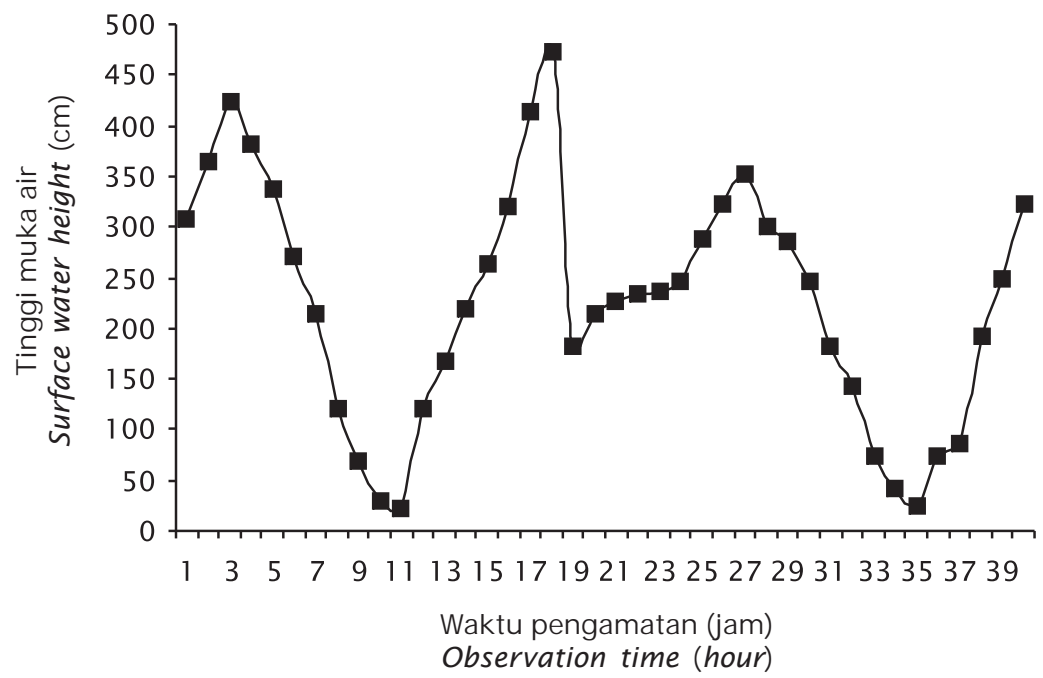

Gambar2. Pasang surut di kawasan pesisir Kabupaten Tanjung Jabung Barat Provinsi Jambi

Figure 2. Tidal range variation in the coastal area of Tanjung Jabung Barat Regency Jambi Province

bahwa lokasi yang fluktuasi pasangnya sedang (kisaran maksimumnya antara 2 dan $3 \mathrm{~m}$ dan rata- rata amplitudonya antara 1,1 dan 2,1 m) adalah layak bagi pengelolaan tambak di kawasan intertidal. Dikatakan pula bahwa lokasi yang fluktuasi pasangnya besar (lebih dari $4 \mathrm{~m}$ ) akan menimbulkan masalah, karena diperlukan pematang yang besar untuk melindungi tambak dari pasang tinggi dan sebaliknya menimbulkan kesulitan mempertahankan air dalam tambak pada saat surut rendah. Kisaran pasang surut antara 1 dan $3 \mathrm{~m}$ lebih baik dalam pengisian serta pengeringan dan pembuangan limbah dari dalam tambak (Chanratchakool et al., 1995). Dengan demikian, pasang surut di kawasan pesisir Kabupaten Tanjabbar tergolong kurang mendukung untuk budidaya tambak.

Suhu air yang terukur di kawasan pertambakan Kabupaten Tanjabbar berkisar antara $25,52^{\circ} \mathrm{C}$ dan $39,97^{\circ} \mathrm{C}$ dengan rata- rata $32,01^{\circ} \mathrm{C}$ (Tabel 1). Suhu air yang tinggi terukur pada tambak dengan air yang sangat dangkal $(<5 \mathrm{~cm})$. Suhu air yang layak untuk budidaya udang windu berkisar antara $26^{\circ} \mathrm{C}$ dan $32^{\circ} \mathrm{C}$ (Poernomo, 1988) serta antara $13^{\circ} \mathrm{C}$ dan $33^{\circ} \mathrm{C}$ (Poxton, 2003) dan optimumnya antara $29^{\circ} \mathrm{C}$ dan $30^{\circ} \mathrm{C}$ (Poernomo, 1988). Suhu air $25^{\circ} \mathrm{C}$ $30^{\circ} \mathrm{C}$ adalah suhu yang baik untuk budidaya rumput laut (Hurtado- Ponce \& Umezaki, 1987).
Oksigen terlarut air di kawasan pertambakan Kabupaten Tanjabbar berkisar antara 5,66 dan 10,21 mg/ L. Oksigen terlarut yang terukur pada siang hari ini dapat mendukung kehidupan organisme budidaya di tambak. Pada konsentrasi oksigen terlarut antara 1,5 dan $3,5 \mathrm{mg} / \mathrm{L}$ dapat menyebabkan pertumbuhan serta konsumsi pakan dan efisiensi pakan pada udang windu menjadi rendah (Tsai, 1989). Batas oksigen terlarut untuk udang windu adalah 3-10 mg/ L dan optimum 4- 7 mg/ L (Poernomo, 1989).

Telah disebutkan sebelumnya bahwa ada tiga sungai besar di Kabupaten Tanjabbar yang bermuara di Selat Berhala di Laut Cina Selatan yang tergolong sungai hidup yang berarti memiliki sumber air tawar. Sebagai akibatnya, salinitas air yang terukur semuanya lebih kecil dari salinitas air laut (<34 ppt) (Tabel 1). Udang windu mampu menyesuaikan diri terhadap salinitas 3-45 ppt (Tseng, 1987 dalam Poernomo, 1988), namun untuk pertumbuhan optimum diperlukan salinitas 15-25 ppt (Poernomo, 1988). Salinitas optimum untuk ikan bandeng (Ismail et al., 1993) adalah 15 sampai dengan 25 ppt. Salinitas optimum untuk rumput laut adalah 15 sampai 25 ppt (Lin, 1974).

Kisaran $\mathrm{pH}$ air di kawasan pertambakan Kabupaten Tanjabbar cukup besar yaitu antara 5,79 dan 10,29 dengan rata- rata 7,21. 
Tabel 1. Kualitas air di kawasan pertambakan $(n=109)$ Kabupaten Tanjung Jabung Barat Provinsi Jambi

Table 1. Water quality in the brackishwater ponds area of Tanjung Jabung Barat Regency Jambi Province

\begin{tabular}{lcccc}
\hline \multicolumn{1}{c}{ Peubah Variables } & Minimum & $\begin{array}{c}\text { Maksimum } \\
\text { Maximum }\end{array}$ & $\begin{array}{c}\text { Ratarata } \\
\text { Average }\end{array}$ & $\begin{array}{c}\text { Standar deviasi } \\
\text { Standard } \\
\text { deviation }\end{array}$ \\
\hline Suhu (Temperature) $\left({ }^{\circ} \mathrm{C}\right)$ & 25.52 & 39.97 & 32.01 & 2.70 \\
Oksigen terlarut & 5.66 & 10.21 & 6.91 & 0.69 \\
Dissolved oxygen (mg/L) & & 23.52 & 9.94 & 6.16 \\
Salinitas (Salinity) (ppt) & 0.72 & 10.29 & 7.21 & 0.89 \\
pH & 5.79 & 357.6 & 113.09 & 87.91 \\
Turbiditas (Turbidity) (NTU) & 20.6 & 0.7757 & 0.0451 & 0.1166 \\
Nitrit (Nitrite) (mg/ L) & 0.0017 & 1.3266 & 0.2388 & 0.3304 \\
Nitrat (Nitrate) (mg/ L) & 0.0027 & 1.5783 & 0.1561 & 0.2273 \\
Amonia (Ammonia) (mg/ L) & 0.0172 & 1.1895 & 0.2053 & 0.2405 \\
Fosfat (Phosphate) (mg/L) & 0.0222 & & & \\
\hline
\end{tabular}

Kemasaman air yang tinggi atau $\mathrm{pH}$ rendah sebagai akibat adanya sumber kemasaman yang dapat berasal dari tanah sulfat masam maupun tanah gambut yang mendominasi tanah di Kabupaten Tanjabbar. Kisaran pH yang baik untuk udang windu adalah 7,5- 8,7 dengan optimum 8,0-8,5 (Poernomo, 1988; 1989). Menurut Swingle (1968), pada umumnya $\mathrm{pH}$ air yang baik bagi organisme akuatik adalah 6,5- 9,0; pada pH 9,5-11,0; dan 4,0- 6,0 mengakibatkan produksi rendah dan jika lebih rendah dari 4,0 atau lebih tinggi 11,0 akan meracuni ikan. Dengan demikian, pH air di kawasan pertambakan Kabupaten Tanjabbar masih dapat mendukung usaha budidaya tambak.

Turbiditas menggambarkan sifat optik air yang ditentukan berdasarkan banyaknya cahaya yang diserap dan dipancarkan oleh bahan- bahan yang terdapat di dalam air. Turbiditas disebabkan oleh adanya bahan organik dan anorganik yang tersuspensi dan terlarut (misalnya lumpur dan pasir halus), maupun bahan anorganik dan organik yang berupa plankton dan mikroorganisme lain (Davis \& Cornwel, 1991; APHA, 2005). Tampaknya, turbiditas air di kawasan pertambakan Kabupaten Tanjabbar tergolong tinggi yang dapat menjadi faktor pembatas dalam budidaya tambak. Turbiditas lebih besar 50 NTU sudah tergolong tinggi dan turbiditas lebih besar 25 NTU sudah dapat mengganggu organisme akuatik (Cech, 2010), Tingginya turbiditas diduga sebagai akibat dari liat lumpur maupun asam- asam humus yang berasal dari gambut.

Konsentrasi nitrit $\left(\mathrm{NO}_{2}\right)$ pada perairan relatif kecil karena segera dioksidasi menjadi nitrat. Perairan alami mengandung $\mathrm{NO}_{2}$ sekitar 0,001 $\mathrm{mg} / \mathrm{L}$ dan sebaliknya tidak melebihi 0,06 $\mathrm{mg} / \mathrm{L}$ (Canadian Council of Resource and Environment Ministers, 1987 dalam Effendi, 2003). Konsentrasi $\mathrm{NO}_{2}$ yang lebih dari 0,05 $\mathrm{mg} / \mathrm{L}$ dapat bersifat toksik bagi organisme akuatik yang sangat sensitif (Moore, 1991). Dengan demikian, konsentrasi nitrit air di beberapa tempat di kawasan pertambakan Kabupaten Tanjabbar tergolong kurang mendukung budidaya tambak, walaupun secara rata-rata konsentrasi nitrit sebesar 0,0451 mg/ L (Tabel 1).

Tidak seperti halnya dengan nitrit yang bersifat toksik, bentuk nitrogen lainnya yaitu nitrat $\left(\mathrm{NO}_{3}\right)$ tidak bersifat toksik terhadap organisme akuatik, bahkan merupakan bentuk utama nitrogen di perairan alami dan merupakan nutrien utama bagi pertumbuhan tanaman dan alga. Konsentrasi $\mathrm{NO}_{3}$ air di kawasan pertambakan Kabupaten Tanjabbar berkisar antara 0,0027 dan 1,3266 dengan ratarata $0,2388 \mathrm{mg} / \mathrm{L}$ (Tabel 1 ) yang menunjukkan bahwa konsentrasi nitrat tergolong tinggi. Telah dilaporkan bahwa konsentrasi $\mathrm{NO}_{3}$ pada 
perairan alami hampir tidak pernah lebih dari $0,1 \mathrm{mg} / \mathrm{L}$. Konsentrasi $\mathrm{NO}_{3}$ yang lebih dari $0,2 \mathrm{mg} / \mathrm{L}$ dapat mengakibatkan terjadinya eutrofikasi perairan yang selanjutnya menstimulir pertumbuhan alga dan tumbuhan air secara pesat (Effendi, 2003).

Konsentrasi amonia $\left(\mathrm{NH}_{3}\right)$ 0,05- 0,20 mg/ L sudah menghambat pertumbuhan organisme akuatik pada umumnya. Apabila konsentrasi $\mathrm{NH}_{3}$ lebih dari $0,2 \mathrm{mg} / \mathrm{L}$, perairan bersifat toksik bagi beberapa jenis ikan (Swayer \& McCarty, 1978). Chanratchakool et al. (1995) menyatakan bahwa konsentrasi $\mathrm{NH}_{3}$ yang diperkenankan untuk budidaya udang windu adalah kurang dari 0,1 mg/L. Dengan demikian, ada tempat tertentu di kawasan pertambakan Kabupaten Tanjabbar yang memiliki konsentrasi $\mathrm{NH}_{3}$ yang tergolong membahayakan kehidupan organisme akuatik, sebab konsentrasinya dapat mencapai 1,5783 $\mathrm{mg} / \mathrm{L}$. .

Konsentrasi fosfat $\left(\mathrm{PO}_{4}\right)$ air di kawasan pertambakan Kabupaten Tanjabbar berkisar 0,0222 dan 1.1695 dengan rata- rata 0,2053 $\mathrm{mg} / \mathrm{L}$. Berdasarkan klasifikasi kesuburan perairan oleh Yoshimura (1966) dalam Liaw (1969), maka konsentrasi $\mathrm{PO}_{4}$ ini tergolong perairan dengan tingkat kesuburan sangat tinggi. Konsentrasi $\mathrm{PO}_{4}$ pada perairan alami berkisar antara 0,005- 0,020 mg/ L (UNESCO/ WHO/UNEP, 1992 dalam Effendi, 2003).

\section{Tanah}

Jenis tanah yang dijumpai di kawasan pertambakan Kabupaten Tanjabbar didominasi oleh tanah sulfat masam dan sebagian kecil tanah gambut dan tanah sulfat masam yang berasosiasi dengan tanah gambut. Karakteristik tanah yang dimiliki tambak di Kabupaten Tanjabbar terlihat pada Tabel 2 .

$\mathrm{pH}_{\mathrm{F}}$ adalah $\mathrm{pH}$ tanah yang diukur di lapangan dalam kondisi tanah jenuh dengan air, sedangkan $\mathrm{pH}_{\mathrm{Fox}}$ adalah $\mathrm{pH}$ tanah yang diukur di lapangan setelah dioksidasi sempurna dengan $\mathrm{H}_{2} \mathrm{O}_{2}$ (hidrogen peroksida) 30\%(Ahern \& Rayment, 1998) dan selisih nilai antara $\mathrm{pH}_{\mathrm{F}}$ dan $\mathrm{pH}_{\mathrm{FOX}}$ dapat digunakan untuk menentukan potensi kemasaman tanah. Ratarata nilai $\mathrm{pH}_{\mathrm{F}}, \mathrm{pH}_{\mathrm{FOX}}$ dan $\mathrm{pH}_{\mathrm{F}}-\mathrm{pH}_{\mathrm{FOX}}$ berturut- turut 6,$26 ; 1,80$ dan 4,46 yang menunjukkan bahwa tanah tambak di Kabupaten Tanjabbar memiliki potensi kemasaman yang tinggi. Hal ini juga didukung dengan nilai $\mathrm{pH}_{\mathrm{KCl}}$ dan $\mathrm{pH}_{\mathrm{Ox}}$ yang rendah serta nilai $S_{P O S}$ dan TPA yang tinggi serta konsentrasi unsur toksik seperti Fe (besi) dan Al (aluminium) yang tinggi juga.

Potensial redoks tanah menggambarkan kondisi tanah yang tereduksi atau teroksidasi. Dari Tabel 2 terlihat bahwa potensial redoks tanah di Kabupaten Tanjabbar bernilai negatif yang berarti tanah dalam kondisi tereduksi. Hal ini sebagai akibat tanah yang telah lama tergenang pada saat pengambilan contoh tanah, sehingga terbentuk kondisi reduksi pada tanah dasar tambak.

Pada tanah sulfat masam yang dicirikan dengan konsentrasi pirit $\left(\mathrm{FeS}_{2}\right)$, maka salah satu sumber kemasamannya adalah sulfur. Pirit yang teroksidasi akan menghasilkan asam sulfat dan ferrosulfat yang apabila bereaksi dengan air melepaskan ferrisulfat yang selanjutnya apabila teroksidasi kembali akan menghasilkan asam sulfat. Dari Tabel 2 terlihat bahwa tanah tambak di Kabupaten Tanjabbar mengandung pirit 2,43 $\pm 1,82 \%$ suatu konsentrasi $\mathrm{FeS}_{2}$ yang tergolong tinggi.

Telah disebutkan sebelumnya bahwa tanah tambak di Kabupaten Tanjabbar selain tergolong tanah sulfat masam juga tergolong tanah gambut atau tanah sulfat masam yang berasosiasi dengan tanah gambut. Hal ini dapat ditunjukkan oleh konsentrasi bahan organik tanah yang cukup tinggi yang dapat mencapai $30,61 \%$ (C- organik 17,71\%). Tanah gambut adalah tanah yang dicirikan dengan konsentrasi C- organik (karbon organik) yang tinggi yaitu melebihi 15\%(Boyd et al., 2002). Konsentrasi bahan organik yang tinggi dapat menyebabkan terbentuknya senyawa metan dan hidrogen sulfida yang merupakan senyawa yang dapat mematikan organisme yang dibudidayakan. Dikatakan oleh Boyd (2008), konsentrasi karbon organik lebih dari $2,5 \%$ sudah termasuk berlebihan dan ada kecenderungan akan terbentuk zona anaerobik di dasar tambak. Dikatakan pula bahwa bahwa konsentrasi karbon organik sebesar 2,5\%termasuk optimum untuk tambak yang dipupuk dan cukup sesuai untuk tambak yang diberi pakan.

Kebanyakan nitrogen dalam tanah dasar tambak terkandung dalam bahan organik. Analisis konsentrasi N- total tanah dilakukan, bukan hanya untuk mengetahui konsentrasi nitrogen tanah, tetapi juga untuk mengetahui rasio C:N tanah. Tampaknya, rasio C: $\mathrm{N}$ tanah tambak di Kabupaten Tanjabbar tergolong sangat tinggi dapat mencapai nilai rata- rata 135. 
Tabel 2. Kualitas tanah (kedalaman 0-0,20 m) tambak di Kabupaten Tanjung Jabung Barat Provinsi Jambi $(\mathrm{n}=105)$

Table 2. Soil quality (at the depth of 0-0.20 m) of brackishwater ponds in Tanjung Jabung Barat Regency Jambi Province

\begin{tabular}{|c|c|c|}
\hline Peubah (Variables) & $\begin{array}{c}\text { Rata-rata } \\
\text { Average }\end{array}$ & $\begin{array}{c}\text { Standar deviasi } \\
\text { Standard deviation }\end{array}$ \\
\hline $\mathrm{pH}_{\mathrm{F}}$ & 6.26 & 0.67 \\
\hline $\mathrm{pH}_{\mathrm{FOx}}$ & 1.8 & 1.1 \\
\hline $\mathrm{pH}_{\mathrm{F}}-\mathrm{pH}_{\mathrm{FOX}}$ & 4.46 & 1.19 \\
\hline Potensial redoks (Redox potential) (mV) & -257 & 114 \\
\hline $\mathrm{pH}_{\mathrm{KCl}}$ & 5.51 & 1.15 \\
\hline $\mathrm{pH}_{\mathrm{OX}}$ & 2.01 & 0.88 \\
\hline $\mathrm{S}_{\mathrm{KCl}}(\%$ & 0.32 & 0.21 \\
\hline $\mathrm{S}_{\mathrm{p}}(\%)$ & 1.67 & 0.86 \\
\hline $\mathrm{S}_{\mathrm{POS}}(\%$ & 1.35 & 0.76 \\
\hline TPA $\left(\mathrm{mol} \mathrm{H}^{+} /\right.$ton $) /\left(\right.$mole $\mathrm{H}^{+} /$ton $)$ & 559 & 390 \\
\hline $\mathrm{TAA}\left(\mathrm{mol} \mathrm{H}^{+} /\right.$ton $) /\left(\right.$mole $\mathrm{H}^{+} /$ton $)$ & 14 & 87 \\
\hline $\mathrm{TSA}\left(\mathrm{mol} \mathrm{H}^{+} /\right.$ton $) /\left(\right.$mole $\mathrm{H}^{+} /$ton $)$ & 545 & 408 \\
\hline Pirit (Pyrite) $(\%$ & 2.43 & 1.82 \\
\hline Bahan organik (Organic matter) $(\%$ & 9,47 & 5.46 \\
\hline $\mathrm{N}$-total $($ Total-N) $(\%$ & 0.05 & 0.02 \\
\hline Rasio C:N (C:N ratio) & 135 & 178 \\
\hline $\mathrm{PO}_{4}(\mathrm{mg} / \mathrm{L})$ & 21.83 & 20.08 \\
\hline $\mathrm{Fe}(\mathrm{mg} / \mathrm{L})$ & 4002 & 1111 \\
\hline $\mathrm{Al}(\mathrm{mg} / \mathrm{L})$ & 198 & 83 \\
\hline Pasir (Sand) $(\%$ & 11 & 10 \\
\hline Liat (Clay) (\% & 53 & 9 \\
\hline Debu (Silt) $(\%$ & 36 & 11 \\
\hline Tekstur (Texture) & \multicolumn{2}{|c|}{$\begin{array}{l}\text { Lempung, Lempung berliat, Lempung berdebu, } \\
\text { Lempung liat berpasir, Pasir berdebu (Loam, Clay } \\
\text { loam, Silty loam, Sandy clay loam, Silty sand) }\end{array}$} \\
\hline
\end{tabular}

Telah dilaporkan sebelumnya bahwa rasio $\mathrm{C}: \mathrm{N}$ tanah gambut biasanya lebih besar dari 31:1 (Mustafa, 1998; Barchia, 2006). Rasio C:N yang ideal untuk tambak adalah 8:1 sampai 12:1 (Boyd, 2008).

Ketersediaan fosfat $\left(\mathrm{PO}_{4}\right)>60 \mathrm{mg} / \mathrm{L}$ dalam tanah tambak dapat digolongkan sebagai slight atau tergolong baik dengan faktor pembatas yang sangat mudah diatasi (Karthik et al., 2005). Oleh karena itu, konsentrasi $\mathrm{PO}_{4}$ di tanah tambak Kabupaten Tanjabbar tergolong rendah sebab rata- rata hanya $21,83 \mathrm{mg} / \mathrm{L}$.

Tanah tambak sering dijumpai bertekstur halus dengan konsentrasi liat minimal 20\% 30\% untuk menahan peresapan ke samping (Boyd, 1995). Tekstur tanah yang baik untuk tambak adalah: liat, lempung berliat, lempung liat berdebu, lempung berdebu, lempung, dan lempung liat berpasir (Ilyas et al., 1987). Dikatakan oleh Boyd (1995) bahwa suatu material tanah yang merupakan campuran dari partikel yang berbeda ukuran dan mengandung minimum 30\%liat adalah ideal untuk konstruksi tambak. Dari Tabel 2 terlihat bahwa tekstur tanah tambak di Kabupaten Tanjabbar adalah lempung, lempung berliat, lempung berdebu, lempung liat berpasir, dan pasir berdebu. Tekstur tanah ini mendukung usaha budidaya tambak yang masih memerlukan makanan alami seperti klekap sebagai sumber utama makanan bagi organisme yang dibudidayakan di tambak. Dalam hal ini, teknologi tradisional dan 
tradisional plus adalah pilihan yang dapat dilakukan di tambak Kabupaten Tanjabbar.

\section{Iklim}

Salah satu faktor yang sangat berpengaruh terhadap budidaya tambak termasuk kualitas air tambak adalah iklim, terutama curah hujan. Curah hujan bulanan di Kabupaten Tanjabbar dapat dilihat pada Gambar 3 dan menunjukkan bahwa setiap bulan terjadi hujan dengan curah hujan melebihi $100 \mathrm{~mm} /$ bulan. Curah hujan bulanan dan hari hujan yang rendah dijumpai pada Februari dan Juni, sedangkan curah hujan dan hari hujan yang lebih tinggi dijumpai pada bulan lainnya.

Curah hujan di Kabupaten Tanjabbar mencapai $2.393 \mathrm{~mm} /$ tahun. Curah hujan antara $2.000-3.000 \mathrm{~mm} /$ tahun dengan bulan kering 2- 3 bulan cukup baik untuk budidaya tambak. Bulan kering di Tanjabbar terjadi pada bulan Februari dan Juni seperti telah disebutkan sebelumnya. Dengan demikian curah hujan di Kabupaten Tanjabbar tergolong mendukung untuk usaha budidaya tambak. Persiapan tambak adalah salah satu kegiatan yang harus dilakukan sebelum dilakukan penebaran. Pada saat persiapan tambak dilakukan pengeringan tambak dengan tujuan untuk memperbaiki sifat fisik tanah, meningkatkan mineralisasi bahan organik dan menghilangkan bahan- bahan beracun berupa hidrogen sulfida, amonia, dan metan. Karena itu diperlukan adanya bulan-bulan kering tertentu pada setiap tahun. Bulan Februari dan Juni adalah saat yang tepat dalam melaksanakan persiapan tambak di Kabupaten Tanjabbar.

\section{Kesesuaian Lahan}

Hasil analisis menunjukkan bahwa tambak yang ada di Kabupaten Tanjabbar seluas 617,14 ha. Dari hasil evaluasi kesesuaian Iahan aktual dari tambak yang ada tersebut ternyata tidak ada lahan tambak yang tergolong sangat sesuai (Kelas S1), 38,40 ha tergolong cukup sesuai (Kelas S2) dan 222,82 ha yang tergolong kurang sesuai (Kelas S3) dan 355,92 ha yang tergolong tidak sesuai (Kelas $\mathrm{N}$ ) (Gambar 4).

Sebagai faktor pembatas utama kesesuaian lahan tambak di Kabupaten Tanjabbar adalah potensi kemasaman tanah yang tinggi. Pengelolaan lahan terutama tanah yang dapat dilakukan untuk menurunkan potensi kemasaman tanah adalah melalui remediasi baik berupa pengeringan dan pembilasan tanah maupun melalui pengapuran. Selain perbaikan tanah, rekayasa tambak yang tepat dapat pula mengoptimumkan produksi di tambak tanah sulfat masam. Untuk mengurangi masuknya asam- asam organik dari pematang

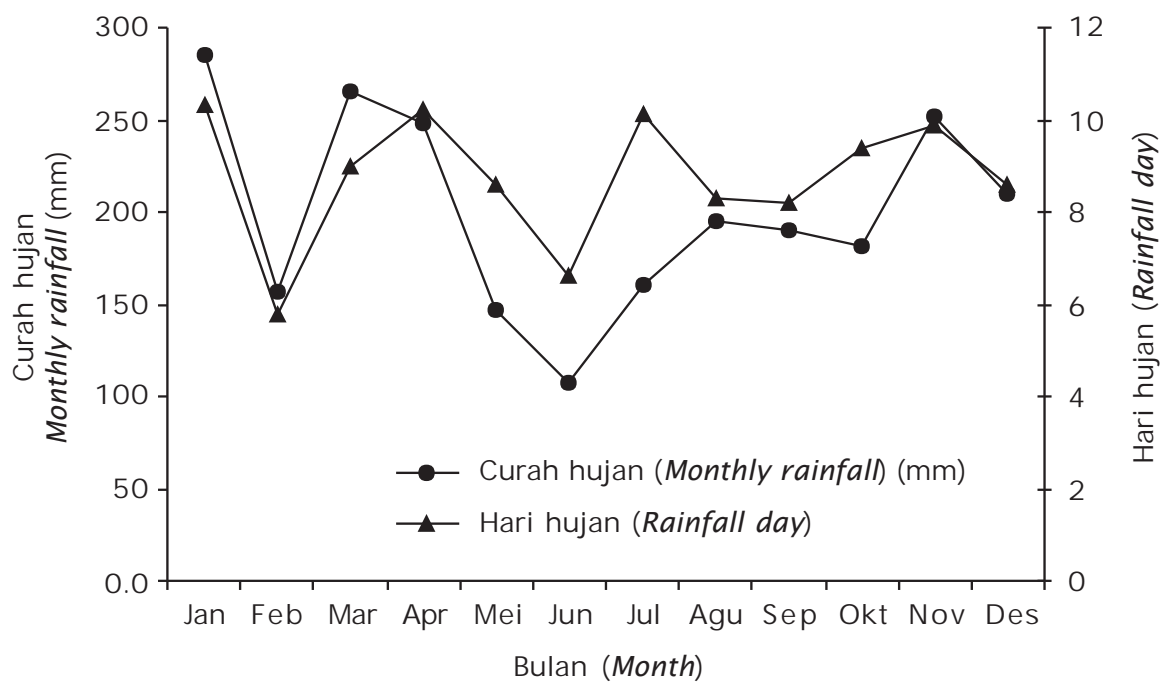

Gambar 3. Curah hujan bulanan di kawasan pesisir Kabupaten Tanjung Jabung Barat Provinsi Jambi

Figure 3. Monthly rainfall in the coastal area of Tanjung Jabung Barat Regency Jambi Province 


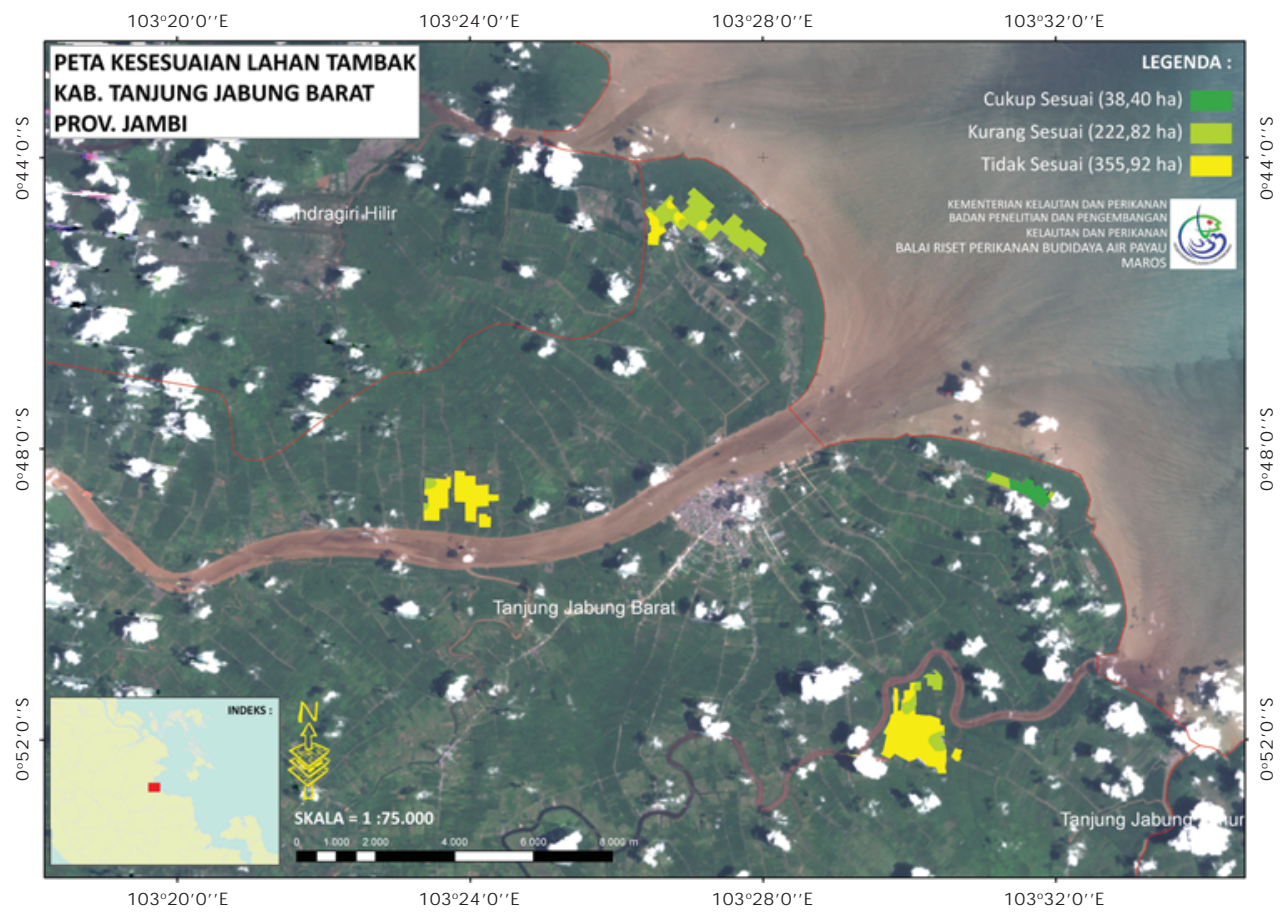

Gambar 4. Kesesuaian lahan aktual tambak yang ada di Kabupaten Tanjung Jabung Barat Provinsi Jambi

Figure 4. Actual land suitability of the existing brackishwater ponds in Tanjung Jabung Barat Regency Jambi Province

ke dalam tambak pada saat hujan (terutama setelah panas yang lama), maka pada tambak tanah sulfat masam sebaiknya pematang diberi berm dan ditanami rumput (Mustafa, 2008). Penanaman rumput pada pematang ini juga dapat mengurangi erosi pematang. Selain itu, untuk mengurangi masuknya asam- asam organik dari dalam tanah pematang tambak yang dibangun di tanah sulfat masam, disarankan melakukan pengapuran berlapis atau integrasi kapur ke dalam tanah pematang pada saat pembuatan pematang baru atau rekonstruksi pematang. Sebaiknya, gundukan tanah yang ada dalam tambak dikurangi dan kalau perlu ditiadakan, sebab kondisi ini menyebabkan semakin luas permukaan tanah sulfat masam yang teroksidasi, sehingga unsur atau senyawa beracun juga semakin bertambah.

Bahan organik tanah yang sangat tinggi juga dapat menjadi faktor pembatas dalam kesesuaian Iahan tambak di Kabupaten Tanjabbar. Penggunaan pupuk yang mengandung nitrogen seperti pupuk Urea diharapkan dapat menurunkan rasio C: $\mathrm{N}$ tanah yang juga dapat mempercepat proses penguraian bahan organik. Penguraian bahan organik dapat pula dipercepat melalui remediasi (Mustafa \& Rachmansyah, 2008).

Pasang surut yang sangat tinggi juga merupakan faktor pembatas dalam pengeIolaan budidaya tambak di Kabupaten Tanjabbar. Pasang surut yang sangat tinggi menuntut pematang tambak yang harus tinggi dan lebar, sehingga konsekuensinya adalah biaya pembuatan dan pemeliharaan tambak yang tergolong tinggi. Pematang utama harus lebih tinggi dari air pasang tertinggi yang pernah terjadi selama 10- 15 tahun terakhir (dela Cruz, 1983). Oleh karena itu, tinggi pematang harus diberi imbuhan atau jagaan 0,3- 0,6 m (Bose et al., 1991). Namun demikian, fraksi liat tanah yang cukup tinggi $(53 \pm 9 \%)$ dapat menjadi material pematang tambak yang baik di Kabupaten Tanjabbar. Tanah tambak dengan konsentrasi liat minimal 20\% 30\% dapat menahan peresapan ke samping (Boyd, 1995). 
Salinitas air yang tergolong relatif rendah untuk budidaya tambak yaitu berkisar antara 0,72 dan 23,52 dengan rata- rata 9,94 ppt dapat menjadi faktor pembatas kesesuaian Iahan tambak di Kabupaten Tanjabbar. Udang windu, udang vaname, dan ikan bandeng merupakan organisme eurihalin, namun karena dibudidayakan untuk tujuan komersial, kisaran salinitas yang optimum perlu dipertahankan. Salinitas optimum untuk udang windu (Poernomo, 1988) dan ikan bandeng (Ismail et al., 1993) adalah 15 sampai dengan 25 ppt. Rumput laut tumbuh optimum pada salinitas 25 ppt (Lin, 1974; Tseng \& Borowitzka, 2003) dan antara 18 dan 30 ppt (Chen, 1976). Tampaknya, komoditas yang dapat beradaptasi terhadap salinitas yang rendah seperti udang windu, udang vaname, ikan bandeng, dan nila merupakan komoditas yang dapat tumbuh dan berkembang pada kondisi salinitas di kawasan pertambakan Kabupaten Tanjabbar.

Turbiditas air sumber yang tinggi juga menjadi faktor pembatas kesesuaian lahan di Tanjabbar. Tampaknya penggunaan petak tandon untuk mengurangi turbiditas air menjadi penting, di samping aplikasi kapur yang juga dapat menurunkan turbiditas air. Turbiditas karena partikel liat tanah dapat dikurangi melalui aplikasi kapur (Masuda \& Boyd, 1999; Ebeling et al., 2003).

Hasil analisis kesesuaian lahan yang telah disebutkan tersebut digolongkan kesesuaian lahan aktual sebab dinilai untuk kondisi saat ini berdasarkan data sifat biofisik lahan sebelum lahan tersebut diberikan masukanmasukan yang diperlukan untuk mengatasi kendala atau faktor pembatas. Apabila usaha perbaikan dapat dilakukan seperti juga telah dijelaskan sebelumnya, maka kelas kesesuaian lahan dapat naik satu tingkat pada golongan kesesuaian Iahan potensial (Ritung et al., 2007).

Pada lokasi yang tergolong cukup sesuai (Kelas S2) disarankan untuk melakukan budidaya udang secara tradisional dan tradisional plus, pada lokasi yang tergolong kurang sesuai (Kelas S3) disarankan melakukan budidaya bandeng atau nila sepanjang tahun atau polikultur rumput laut dengan bandeng pada musim kemarau.

Berdasarkan Pasal 27 Keppres Nomor 32 tahun 1990 tentang Pengelolaan Kawasan Lindung dan kisaran pasang surut di Kabupaten Tanjabbar maka lebar jalur hijau di tepi pantai sekitar $592 \mathrm{~m}$ dan berdasarkan
Pasal 16 Keppres Nomor 32 tahun 1990 tentang Pengelolaan Kawasan Lindung maka lebar jalur hijau di tepi kiri dan kanan Sungai Pengabuan, Sungai Tungkal, dan Sungai Betara adalah $100 \mathrm{~m}$. Pada Pasal 13 Penjelasan UU RI Nomor 31 (2004) dikatakan bahwa salah satu kawasan konservasi yang terkait dengan perikanan adalah mangrove.

\section{KESIMPULAN DAN SARAN}

Hasil karakterisasi lahan tambak di Kabupaten Tanjung Jabung Barat Provinsi Jambi menunjukkan bahwa tanah sulfat masam adalah jenis tanah dominan yang memiliki potensi kemasaman dan unsur- unsur toksik yang tinggi dan sebaliknya unsur hara makro yang rendah dengan tekstur tanah dominan yang tergolong pasir berlempung dan lempung berpasir. Topografi lahan umumnya relatif datar dan elevasi yang tergolong rendah. Salinitas air tergolong rendah dengan tingkat turbiditas yang tergolong tinggi serta pasang surut yang sangat tinggi $(4,55 \mathrm{~m})$. Curah hujan yang mencapai $2.393 \mathrm{~mm} /$ tahun dengan 2 bulan kering. Hasil analisis menunjukkan bahwa tambak yang ada di Kabupaten Tanjabbar seluas 617,14 ha, di mana tidak ada lahan tambak yang tergolong sangat sesuai (Kelas S1), 38,40 ha tergolong cukup sesuai (Kelas S2) dan 222,82 ha yang tergolong kurang sesuai (Kelas S3) dan 355,92 ha yang tergolong tidak sesuai (Kelas $\mathrm{N}$ ).

\section{UCAPAN TERIMA KASIH}

Diucapkan terima kasih kepada Idham Halid, Makmur, dan Mat Fahrur atas bantuannya dalam pengukuran dan pengambilan contoh tanah dan air maupun pengukuran pasang surut di lapangan; Rosiana Sabang, Kamariah, Rahmiyah, dan Rismawati atas bantuannya dalam analisis kualitas tanah serta Sutrisyani, Siti Rohani, Andi Sahrijanna, dan Kurniati atas bantuannya dalam analisis kualitas air di laboratorium. Terima kasih juga diucapkan pada Kepala dan Staf Dinas Kelautan dan Perikanan Kabupaten Tanjung Jabung Barat atas segala bantuannya selama pelaksanaan penelitian di lapangan.

\section{DAFTAR ACUAN}

Agus, F., Yusrial \& Sutono. 2006. Penetapan tekstur tanah. Dalam: Kurnia, U., Agus, F., Adimihardja, A. dan Dariah, A. (Eds.), Sifat Fisik Tanah dan Metode Analisisnya. Balai Besar Penelitian dan Pengembangan 
Sumberdaya Lahan Pertanian, Bogor. hlm. 43- 62.

Ahern, C.R. \& Blunden. B. 1998. Designing a soil sampling and analysis program. In: Ahern, C.R., Blunden, B. and Stone, Y. (eds.), Acid Sulfate Soils Laboratory Methods Guidelines. Acid Sulfate Soil Management Advisory Committee, Wollongbar, NSW. p. 2.1-2.6.

Ahern, C.R. \& McElnea, A.E. 2004. Calculated sulfur parameters. In: Acid Sulfate Soils Laboratory Methods Guidelines. Queensland Department of Natural Resources, Mines and Energy, Indooroopilly, Queensland, Australia. p. B11- 1-B11- 2.

Ahern, C.R., McElnea, A., \& Baker, D.E. 1998a. Peroxide oxidation combined acidity and sulfate. In: Ahern, C.R., B. Blunden and Y. Stone (eds.), Acid Sulfate Soils Laboratory Methods Guidelines. Acid Sulfate Soil Management Advisory Committee, Wollongbar, NSW. p. 4.1-4.17.

Ahern, C.R., McElnea, A.E., \& Baker, D.E. 1998b. Total oxidisable sulfur. In: Ahern, C.R., Blunden, B. and Stone, Y. (eds.), Acid Sulfate Soils Laboratory Methods Guidelines. Acid Sulfate Soil Management Advisory Committee, Wollongbar, NSW. p. 5.1-5.7.

Ahern, C.R. \& Rayment, G.E. 1998. Codes for acid sulfate soils analytical methods. In: Ahern, C.R., Blunden, B. and Stone, Y. (eds.), Acid Sulfate Soils Laboratory Methods Guidelines. Acid Sulfate Soil Management Advisory Committee, Wollong bar, NSW. p. 3.1-3.5.

Anonim. 2009. Geografi dan Iklim Kabupaten Tanjung Jabung Barat, 2009. http:// tanjabbarkab.bps.go.id/index.php/ geografi.html. Diakses 12/02/2011.

APHA (American Public Health Association). 2005. Standard Methods for Examination of Water and Wastewater. APHA- AWWA- WEF, Washington, DC. 1185 pp.

Bose, A.N., Ghosh, S.N., Yang, C.T., \& Mitra, A. 1991. Coastal Aquaculture Engineering. Oxford \& IBH Publishing Co. Pvt. Ltd., New Delhi. 365 pp.

Boyd, C.E. 1995. Bottom Soils, Sediment, and Pond Aquaculture. Chapman and Hall, New York. 348 pp.

Boyd, C.E. 2008. Pond bottom soil analyses. Global Aquaculture Advocate September/ October, 91- 92.

Boyd, C.E., Wood, C.W., \& Thunjai, T. 2002. Aquaculture Pond Bottom Soil Quality
Management. Oregon State University, Corvallis, Oregon. 41 pp.

Barchia, M.F. 2006. Gambut: Agroekosistem dan Transformasi Karbon. Gadjah Mada University Press, Yogyakarta. $196 \mathrm{hlm}$.

Cech, T.V. 2010. Principles of Water Resources: History, Development, Management and Policy. Third edition. John Wiley \& Sons, Inc. Hoboken. 549 pp.

Chanratchakool, P., Turnbull, J.F., Funge- Smith, S., \& Limsuwan, C. 1995. Health Management in Shrimp Ponds. Second edition. Aquatic Animal Health Research Institute, Department of Fisheries, Kasetsart University Campus, Bangkok. 111 pp.

Chen, T.P. 1976. Culture of Gracilaria. In: Aquaculture Practices in Taiwan. Page Bros., London. p. 145- 149.

Davis, M.L. \& Cornwell, D.A. 1991. Introduction to Environmental Engineering. Second edition. McGraw- Hill, Inc., New York. 822 pp.

dela Cruz, C.R. 1983. Fishpond Engineering: A Technical Manual for Small- and Mediumscale Coastal Fish Farms in Southeast Asia. South China Sea Fisheries Development and Coordinating Programme, Manila. 180 $\mathrm{pp}$.

Ebeling, J.M., Sibrell, P.L., Ogden, S.R., \& Summerfelt, S.T. 2003. Evaluation of chemical coagulation- flocculation aids for the removal of suspended solids and phosphorus from intensive recirculating aquaculture effluent discharge. Aquacultural Engineering, 29: 23- 42.

Effendi, H. 2003. Telaah Kualitas Air bagi Pengelolaan Sumber Daya dan Lingkungan Perairan. Penerbit Kanisius, Yogyakarta. $258 \mathrm{hlm}$.

FAO (Food and Agriculture Organization). 1985. Guidelines: land evaluation for irrigated agriculture. In: FAO Soil Bulletin 55. Soil Resources Management and Conservation Service and Water Development Division, FAO, Rome. 231 pp.

Hardjowigeno, S. 2003. Klasifikasi Tanah dan Pedogenesis. Edisi Revisi. Akademika Pressindo, Jakarta. $354 \mathrm{hlm}$.

Hossain, M.S. \&Das, N.G. 2010. GIS- based multicriteria evaluation to land suitability modelling for giant prawn (Macrobrachium rosenbergii) farming in Companigonj Upazila of Noakhali, Bangladesh. Computers and Electronics in Agriculture, 70(1): 172- 186. 
Hurtado- Ponce, A.Q. \&Umezaki, I. 1987. Growth rate studies of Gracilaria verrucosa (Gigartinales, Rhodophyta). Botanica Marina, 30: 223- 226.

Ilyas, S., Cholik, F., Poernomo, A., Ismail, W., Arifudin, R., Daulay, T., Ismail, A., Koesoemadinata, S., Rabegnatar, I N.S., Soepriyadi, H., Suharto, H.H., Azwar, Z.I., \& Ekowardoyo, S. 1987. Petunjuk Teknis bagi Pengoperasian Unit Usaha Pembesaran Udang Windu. Pusat Penelitian dan Pengembangan Perikanan, Jakarta. $100 \mathrm{hlm}$.

Ismail, A., Poernomo, A., Sunyoto, P., Wedjatmiko, Dharmadi, \& Budiman, R.A.I. 1993. Pedoman Teknis Usaha Pembesaran Ikan Bandeng di Indonesia. Pusat Penelitian dan Pengembangan Perikanan, Jakarta. $93 \mathrm{hlm}$.

Karthik, M., Suri, J., Saharan, N., \& Biradar, R.S. 2005. Brackish Water Aquaculture Site Selection in Palghar Taluk, Thane district of Maharashtra, India, Using the Techniques of Remote Sensing and Geographical Information System. Aquacultural Engineering, 32:285- 302.

Liaw, W.K. 1969. Chemical and biological studies of fishponds and reservoirs in Taiwan. Rep. Fish Culture Res., Fish. Series, Chin. Am. Joint Commission on Rural Reconstruction, 7: 1- 43.

Lin, M.N. 1974. Culture of Gracilaria. Fish Research Institute, Keelung, Taipei. p. 1-8.

Masuda, K. \& Boyd, C.E. 1999. Effect of aeration, alum treatment, liming, and organic matter application on phosphorus exchange between soil and water in aquaculture ponds at Auburn, Alabama. Journal of the World Aquaculture Society, 25(3): 405416.

McElnea, A.E. \& Ahern, C.R. 2004a. KCl extractable $\mathrm{pH}\left(\mathrm{pH}_{\mathrm{KC}}\right)$ and titratable actual acidity (TAA). In: Acid Sulfate Soils Laboratory Methods Guidelines. Queensland Department of Natural Resources, Mines and Energy, Indooroopilly, Queensland, Australia. p. B2- 1- B2- 3.

McElnea, A.E. \& Ahern, C.R. 2004b. Peroxide $\mathrm{pH}\left(\mathrm{pH}_{\mathrm{ox}}\right)$, titartable peroxide acidity (TPA) and excess acid neutralising capacity $\left(\mathrm{ANC}_{\mathrm{E}}\right.$ ). In: Acid Sulfate Soils Laboratory Methods Guidelines. Queensland Department of Natural Resources, Mines and Energy, Indooroopilly, Queensland, Australia. p. B3-1-B3-7.

McElnea, A.E. \& Ahern, C.R. 2004c. Sulfurperoxide oxidation method. In: Acid Sulfate
Soils Laboratory Methods Guidelines. Queensland Department of Natural Resources, Mines and Energy, Indooroopilly, Queensland, Australia. p. B7- 1- B7- 2.

McElnea, A.E. \& Ahern, C.R. 2004d. Sulfur 1M $\mathrm{KCl}$ extraction $\left(\mathrm{S}_{\mathrm{KCl}}\right)$. In: Acid Sulfate Soils Laboratory Methods Guidelines. Queensland Department of Natural Resources, Mines and Energy, Indooroopilly, Queensland, Australia. p. B8- 1- B8- 2.

Melville, M.D. 1993. Soil Laboratory Manual. School of Geography, The University of New South Wales, Sydney. 74 pp.

Menon, R.G. 1973. Soil and Water Analysis: A Laboratory Manual for the Analysis of Soil and Water. Proyek Survey O.K.T. Sumatera Selatan, Palembang. 190 pp.

Moore, J.W. 1991. Inorganic Contaminants of Surface Water. Springer- Verlag, New York. $334 \mathrm{pp}$.

Mustafa, A. 1998. Budi daya tambak di lahan gambut dan permasalahannya: studi kasus di Sulawesi Selatan. Jurnal Litbang Pertanian, XVII(3): 73- 82.

Mustafa, A. 2008. Desain, tata letak dan konstruksi tambak. Media Akuakultur, 3(2): 166- 174.

Mustafa, A. \& Rachmansyah. 2008. Kebijakan dalam pemanfaatan tanah sulfat masam untuk budidaya tambak. Dalam: Sudradjat, A., Rusastra, I W. dan Budiharsono, S. (eds.), Analisis Kebijakan Pembangunan Perikanan Budidaya. Pusat Riset Perikanan Budidaya, Jakarta. hlm. 1- 11.

Mustafa, A., Rachmansyah, \& Hanafi, A. 2007. Kelayakan Lahan untuk Budi Daya Perikanan Pesisir. Dalam: Kumpulan Makalah Bidang Riset Perikanan Budidaya. Disampaikan pada Simposium Kelautan dan Perikanan pada tanggal 7 Agustus 2007 di Gedung Bidakara, Jakarta. Pusat Riset Perikanan Budidaya, Jakarta. $28 \mathrm{hlm}$.

Pérez, O.M., Ross, L.G., Telfer, T.C., \& del Campo Barquin, L.M. 2003. Water quality requirements for marine fish cage site selection in Tenerife (Canary Islands): predictive modelling and analysis using GIS. Aquaculture, 224: 51- 68.

Poernomo, A. 1988. Pembuatan Tambak Udang di Indonesia. Seri Pengembangan No. 7. Balai Penelitian Perikanan Budidaya Pantai, Maros. $30 \mathrm{hlm}$.

Poernomo, A. 1989. Faktor lingkungan dominan pada budidaya udang intensif. Dalam: 
Bittner, A. (Ed.), Budidaya Air. Yayasan Obor Indonesia, Jakarta. hlm. 66- 120.

Poxton, M. 2003. Water quality. In: Lucas, J.S. and Southgate, P.C. (eds.), Aquaculture: Farming Aquatic Animals and Plans. Blackwell Publishing Ltd., Oxford. p. 47- 73.

Rajitha, K., Mukherjee, C.K. \& Chandran, R.V. 2007. Applications of remote sensing and GIS for sustainable management of shrimp culture in India. Aquacultural Engineering, 36: 1-17.

Ritung, S., Wahyunto, Agus, F. \& Hidayat, H. 2007. Panduan Evaluasi Kesesuaian Lahan dengan Contoh Peta Arahan Penggunaan Lahan Kabupaten Aceh Barat. Balai Penelitian Tanah dan World Agroforestry Centre (ICRAF), Bogor, Indonesia. $39 \mathrm{hlm}$.

Rossiter, D.G. 1996. A theoretical framework for land evaluation. Geoderma, 72: 165202.
Sawyer, C.N. \& McCarty, P.L. 1978. Chemistry for Environmental Engineering. Third edition. McGraw- Hill Book Company, Tokyo. $532 \mathrm{pp}$.

Sulaeman, Suparto, \& Eviati. 2005. Petunjuk Teknis Analisis Kimia Tanah, Tanaman, Air, dan Pupuk. Dalam: Prasetyo, B.H., Santoso, D. dan Widowati, L.R. (Eds.). Balai Penelitian Tanah, Bogor. $136 \mathrm{hlm}$.

Swingle, H.S. 1968. Standardization of chemical analysis for waters and pond muds. FAO Fisheries Report, 44(4): 397- 406.

Tsai, C. -K. 1989. Water quality management. In: Akiyama, D.M. (ed.), Proceedings of the Southeast Asia Shrimp Farm Management Workshop. American Soybean Association, Singapore. p. 56- 63.

Tseng, C.K. \& Borowitzka, M. 2003. Algae culture. In: Lucas, J.S. and Southgate, P.C. (eds.), Aquaculture: Farming Aquatic Animals and Plants. Blackwell Publishing Ltd., Oxford. p. 253- 275. 